\title{
A review of Simi Linton (1998) claiming disability: knowledge and identity
}

\begin{abstract}
In Claiming disability: knowledge and identity, Simi Linton invites us to reconsider the meanings we give to disability and to elaborate more on their origins. She consistently demonstrates how society and academia take a narrow, devaluing construction of disability. This limited view affects our language and academic curriculum, and therefore serves to increase both marginalization and discrimination of persons with disabilities. Linton advocates a vision that she states as a new field of thought called Disability Studies. In my opinion, a more in depth and comprehensive incorporation and inclusion of research on disability studies in social sciences, society studies, and academic fields would definitely increase the role and effectiveness of society and academia in decreasing the gap between disabled and non-disabled, increasing the level of people's awareness and perception of disability, and in providing a better understanding of disability across the cultures through the promotion of appropriate educational practices and behaviors.
\end{abstract}

Volume I Issue 5 - 2018

\author{
Hassan Izzeddin Sarsak \\ Department of Occupational Therapy, School of Rehabilitation \\ Sciences, University of Jordan, Jordan
}

Correspondence: Hassan Izzeddin Sarsak, Department of Occupational Therapy, Batterjee Medical College, Jeddah, KSA,Email h.sarsak@ju.edu.jo, hassan.sarsak@bmc.edu.sa, sarsakhassan@gmail.com

Received: August 31, 2018 | Published: September 17, 2018

Keywords: disability, people with disabilities, discrimination, advocacy, society, inclusion

\section{Introduction}

Simi Linton's ${ }^{1}$ Claiming disability surely constitutes a key endeavor in understanding disability, the cultural and political arena. The common man looks at disability as a special or specific category and believes the society to be divided into two sections, disabled and non-disabled. Disability can happen to anyone at any time, however, non-disabled section of the society generally find it difficult to appreciate this fact or consider the causes, effects, representations and ramifications of disability. Linton through this book has tried to point out that disability studies should not just be part of applied fields like rehabilitation and social work, but rather they be liberal arts, the humanities, and the general education. As a field of just a specific section, Disability law should therefore be part of public policy and public law. Disability should be part of social debate and social construction just as gender, race and sexual orientation are. It is quite common for the non-disabled section of the society to consider gender, race and sexual orientation as part of universal human rights; however, disability law is generally not regarded to part of establishing egalitarian civil rights in a social democracy. Simi Linton stresses in this book that disability should be central to humanities at universities and this might eventually lead to disability to being central to humanity.

The academic system and legislature are responsible for disabled people's compromised position. This book looks at disability studies as a field of inquiry examining its historical roots, contemporary state and value. Disability studies constitute the appropriate knowledge base to study the construction and function of disability. Disability studies examine the variation in human behavior and functioning. It critically examines the meaning society attributes to these variations and the wait divides the population into the disabled and non-disabled, the normal and the pathological, the competent and ward of state. Disability studies and the disability rights movement have together created new paradigms used to understand disability as a social, cultural and political phenomenon. Disability studies have grown in the last two decades as an organized critique o the constricted, marginalized, inaccurate and inadequate conceptualization of disability in academia. Disability studies challenge and critique the medicalization of disability and points to the inadequacy of the entire curriculum in understanding disability.

\section{Summary}

\section{Reclamation}

As the name suggests this section introduces the subordinate, secondary and special status given to disability in society and academia. The critique draws the reader's attention to the inaccuracies and inadequacies in the current system and the need to claim the correct meaning and approach toward disability as a socio cultural and political phenomenon.

\section{Reassigning meaning}

This section talks about use of language and terms which are socially and economically convenient to the society. The section opens with the medical meaning making of disability and goes on to describe the implications of the current terminology. The reader is introduced to terms like Ableism which according to the Oxford word finder is discrimination in the favor of the non-disabled." Central to the argument of this book this section gives an insight into attributing correct meaning and status to disability.

\section{Divided society}

The underlying ethos of this section emphasizes the current practice to marginalize and subordinate disable people. This section not only draws parallels between disability, race, and gender issues but also describes the variations that have existed in social arrangements throughout history and the in contemporary society.

\section{Divided curriculum}

This section elaborates the subordinate position of disabled people in critical, social and economic domain. Attention is drawn to the recognition of the fact that the histories and legacies of disabled people have been distorted. The chapter examines the traditions and barriers to a meaningful and study of disability.

\section{Entered disability studies}

This discourse elaborates the creation of Disability studies as a knowledge base to study disability as a social, cultural and political phenomenon. The section describes how disability studies can help develop a fair and impartial understanding of human society and 
understand the significance of variation in the human experience.

\section{Disability studies/not disability studies}

Disability studies arose in part due to the medicalization of disability. This section talks about having rational and coherent border to mark disability as a socio, cultural and political examination of variation in human experience.

\section{Applications}

This section of the book presents the reader with various thought provoking scenarios involving disability issues. The idea is to highlight the fact that only when disability studies become a part of liberal arts, humanities, in other words the entire curriculum, will it be possible for the nondisabled section of the society to deal appropriately and fairly with disability issues.

\section{Critique}

Simi Linton is a renowned author in the field of disability studies, professor in psychology and a wheelchair user herself. She has had a great deal of experience in working in the field of disability, as a member, as an advocate and as a think tank for future direction. She taught at Hunter University earlier in her career and is currently a professor at Columbia University. Claiming Disability is a landmark book in providing the framework, in attempting the amorphous and seemingly indomitable task of affording disability the status of a socio-cultural and political phenomenon. The strengths of this book far outweigh the weaknesses if any. This book is so well written and argued that it is difficult to find flaws. Nevertheless I believe that although the framework suggested by Linton to give disability and disability studies an appropriate status is very good and visionary, however, there isn't a clear enough outline of how this huge task can be accomplished. Although the book is very well wrapped up by examples and quotations, however I do believe that it does lack evidence in the form of statistical data and a global perspective. "The curriculum is a manifest expression of cultural values just as laws are manifest expressions of what a society deems to be right or wrong behavior." Clebard 1992 page 199. This quote captures the central argument of this book as we begin to talk of the strengths of this book. Disability is one variable amongst the many in the human experience.
Therefore disability and disability studies should be considered central to humanity. Unless and until disability studies become a part of liberal arts and humanities, they won't become a central part of the entire curriculum and of humanity. The stress in Linton's book on incorporating disability studies would be critical in forging ahead to make a society where disability is not regarded as a defeat, sadness, a loss but rather a variation of human experience.

Another key strength of this book is the stress it lays on the participation of disabled individuals in all spheres of life. This participation would only be significant if the disabled individuals come together to be part of the Disability Rights Movement. The force of working together to advocate for justice and fairness for all would be critical to establish a world where disabled individuals are not looked down upon as a marginalized and disadvantaged section. Linton's stress on this coming together would lay the foundation for disabled individuals leading a life of dignity and parity. Linton, a professor in psychology has demonstrated in this book depth of knowledge and expertise to slip in and out of different fields of academia in making her point. Her book is a very fair and balanced argument weighing the pros and cons of each situation and backing it up with relevant data, both historical and contemporary.

\section{Conclusion}

Claiming disability is sure to be a landmark book in the wake of Americans with Disabilities Act (ADA) of 1990. This book has very boldly and coherently given the reader a framework of how to surmount the amorphous task of making disability a part of the entire curriculum, human experience and thus humanity.

\section{Acknowledgements}

None.

\section{Conflict of interest}

Author declares that there is no conflict of interest.

\section{Reference}

1. Linton S. Claiming disability: knowledge and identity. New York: NYU Press; 1998. 